\title{
ARTICLES
}

\section{A STUDY TO ASSESS THE KNOWLEDGE, ATTITUDE AND PRACTICE REGARDING PREVENTION OF FOOT COMPLICATIONS AMONG PATIENTS WITH DIABETES MELLITUS BEFORE AND AFTER VIDEO ASSITED PROGRAMME}

\author{
Mrs. Rosemine Kiruba Darwin* | Dr. Santhi Appavu** \\ * Ph.D. Scholar, Himalayan University, Itanagar, Arunachal Pradesh, India. \\ **Research Supervisor, Himalayan University, Itanagar, Arunachal Pradesh, India. \\ DOI: http://doi.org/10.47211/trr.2019.v05i02.015 \\ Received $20^{\text {th }}$ November 2019, Accepted $5^{\text {th }}$ December 2019, Published $20^{\text {th }}$ December 2019
}

\begin{abstract}
The study has been under taken to evaluate the effectiveness of Video Assisted Teaching Programme on knowledge, attitude and practice regarding the prevention of foot complications among patients with Diabetes Mellitus in selected diabetic clinic at Kanyakumari District. The study was conducted by the Research Ph.D. scholar in partial fulfillment of the Philosophy in Nursing at Himalayan University, Arunachal Pradesh, during 2016-2019.

Objective Of The Study: To Assess The Knowledge, Attitude And Practice Regarding Prevention Of Foot Complications Among Patients With Diabetes Mellitus Before And After Administration Of Video Assisted Teaching Programme. Conceptual Frame Work: The conceptual frame work selected for this study is based on Pender's model of health promotion (redrawn from Pender $N \mathrm{~J}$ : health promotion in nursing practice.1996). Health promotion is directed at increasing a client level of well-being (Pender 1996). The conclusions were drawn from the findings of the study are; statistically proved that video assisted Programme is more effective in changing the level of knowledge of diabetic cases. Statistically proved that video assisted Programme is more effective in changing the attitude and practice of diabetic cases.
\end{abstract}

Key Words: Video Assisted Teaching Programme, knowledge, attitude, practice, prevention of foot complications.

ABOUT AUTHORS:

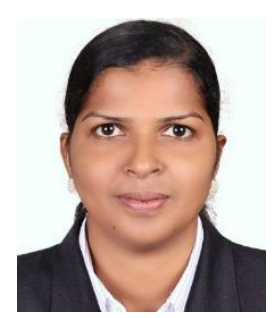

The author Mrs. Rosemine Kiruba Darwin is research scholar, Himalayan University, Itanagar, Arunachal Pradesh, India.

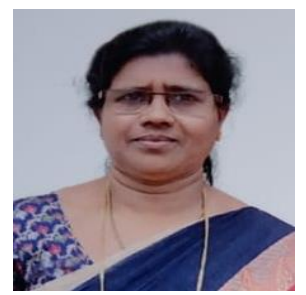

The author Dr. Santhi Appavu is research guide, Himalayan University, Itanagar, Arunachal Pradesh, India. She has presented papers in various national and international conferences. 


\section{ARTICLES}

\section{INTRODUCTION}

Foot problems are a common complication in people with diabetes. Fortunately, most of these complications can be prevented with careful foot care. If complications do occur, daily attention will ensure that they are detected before they become serious. It may take time and effort to build good foot care habits, but self-care is essential in fact when it comes to foot care, the patient is a vital member of the medical team. India has the largest diabetic population of 50.8 million that could reach an epidemic range by 2030. Diabetic foot infection is the most dreaded complications of diabetes. Diabetic foot ulcers and their consequences do not only represent a major personal tragedy for the person suffering from an ulcer and his/her family they also place a considerable financial burden on the health care system and society in general. Ulcers of the foot in diabetes are the source of major suffering and cost. At least one quarter will not heal and up to 28 percent may result in any form of amputation. Investing in diabetic foot care guideline is therefore the most cost effective forms of health care expenditure, provided the guideline is goal focus international working group on the diabetic foot.

\section{NEED FOR THE STUDY}

Video assisted teaching is an effective Programme. Through this Programme people gain knowledge on self-care activities. Hence the above information signifies the information burden of diabetes mellitus and its various complications which brought the researchers attention to select the title. The recent trend in nurse's role is extended and expanded. Nurses'play a major role in prevention of diseases helps in reducing the mortality rate and improvement of quality of life. When the researcher had the clinical experience with the diabetic patients and identified they have lack of knowledge on foot complications and how to preventive it, this was made the researcher to do a research on this selected problem for research. Hence assessing the knowledge of diabetic foot care among diabetics will support to put the knowledge into practice. To evaluate the effectiveness of video assisted teaching programme on =diabetic foot care'among the subjects. It has been observed at the selected health facility that diabetic foot care education is not carried out using a consistent standardized program. There is very little or no structured formal education for diabetic patients', especially concerning foot care. It was also observed that the little foot care education provided followed a traditional outline of a nurse lecture without demonstration or feedback from patients and no follow up on education result. This research will seek to explore the efficacy of using a Video Assisted Teaching Program (VATP) for foot care education as a means of public education for diabetic patients to determine the significant role if any on the foot care practices in prevention Of lower limb amputations and ulcers among diabetics.

\section{STATEMENT OF PROBLEM}

“A STUDY TO ASSESS THE KNOWLEDGE, ATTITUDE AND PRACTICE REGARDING PREVENTION OF FOOT COMPLICATIONS AMONG PATIENTS WITH DIABETES MELLITUS BEFORE AND AFTER VIDEO ASSITED PROGRAMME." 


\section{ARTICLES}

\section{OBJECTIVES.}

To Assess The Knowledge, Attitude And Practice Regarding Prevention Of Foot Complications Among Patients With Diabetes Mellitus Before And After Administration Of Video Assisted Teaching Programme.

\section{RESEARCH METHODOLOGY}

Research Approach: Quasi experimental approach was used for the present study

Research Design: Quasi-experimental research design was used to assess Video assisted teaching Programme regarding prevention of foot complications of diabetes mellitus.

Research Setting: The present study was conducted in Kanyakumari Medical Mission outpatient department of Diabetic clinic. It is situated in Neyyoor, Kanyakumari district, Tamilnadu.

Study Population: Target population of study was family members of the patients.

Sample Size: Total population of the present research is 250 patients. The patients who are having

Type I or type II diabetes mellitus in the selected diabetic clinic.

Sampling Technique: Non-probability convenience sampling, in which the convenient sampling technique was adopted for this study. The researcher planned to select the most readily available persons meeting the inclusion criteria as participants in the study.

\section{Development and Description of Research Tool:}

\section{Knowledge Questionnaire:}

Knowledge Questionnaire consisted of 30 items on prevention of foot complications of diabetes mellitus. Each item will be having one correct response. Score $=^{1}{ }^{\prime}$ will be allotted for correct answer and $=0^{\prime}$ for wrong answer. The scoring system is divided into the three categories

Adequate Knowledge - 76-100\%

Moderate Knowledge - 51-75\%

Inadequate Knowledge - Below 50\%

\section{Attitude Scale:}

Attitude Scale consisted of 20 items on prevention of foot complications of diabetes mellitus. The score was ranged from 4 to 0 (Strongly agree, disagree, strongly disagree).

The scoring system is divided into the three categories

Most desirable Attitude - 76-100\%

Desirable Attitude - 51-75\%

Undesirable Attitude - Below 50\%

\section{Practice Scale:}

Four-point Likert Scale, Scale consisted of 15 items. Score ranged from 1 to 4 (Never, Some time, often, and always).

The scoring system is divided into the three categories Good practice - 76-100\% 


\section{ARTICLES}

Average practice - $51-75 \%$

Poor practice - Below 50\%

\section{Discussions}

Mean trends of knowledge within and between of both groups

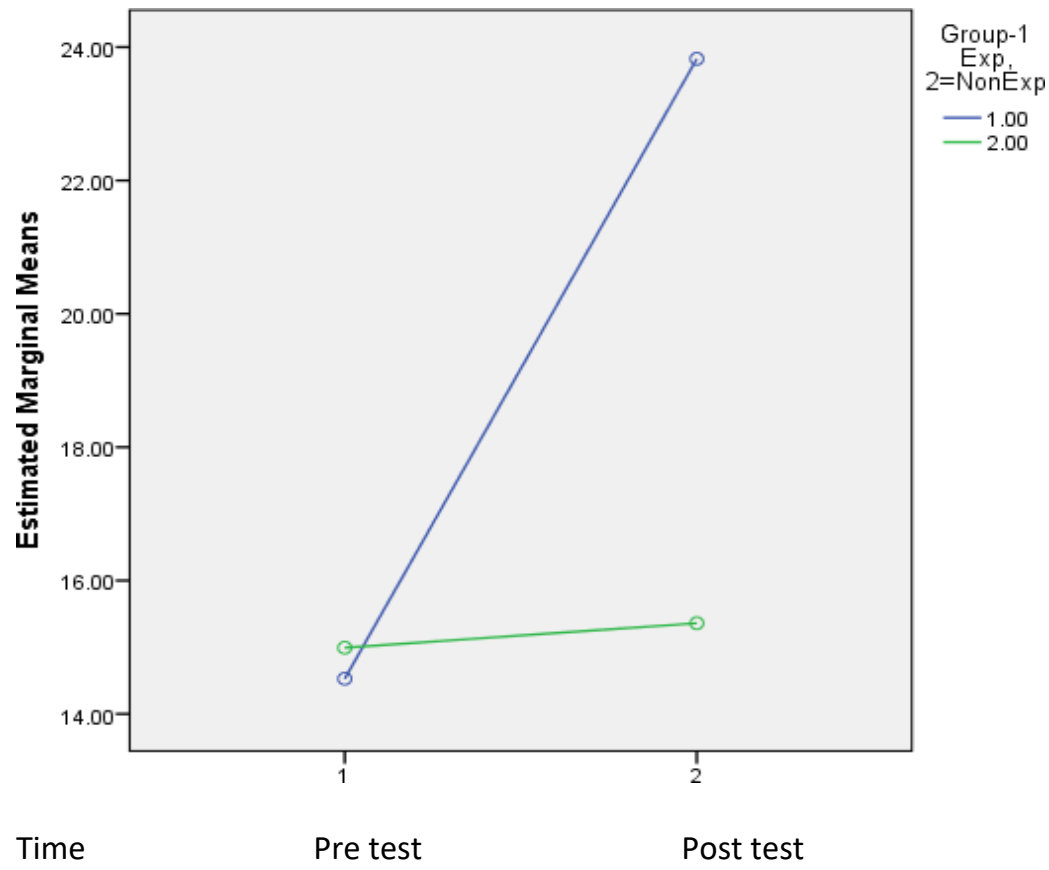

Trends of mean attitude within and between of both groups

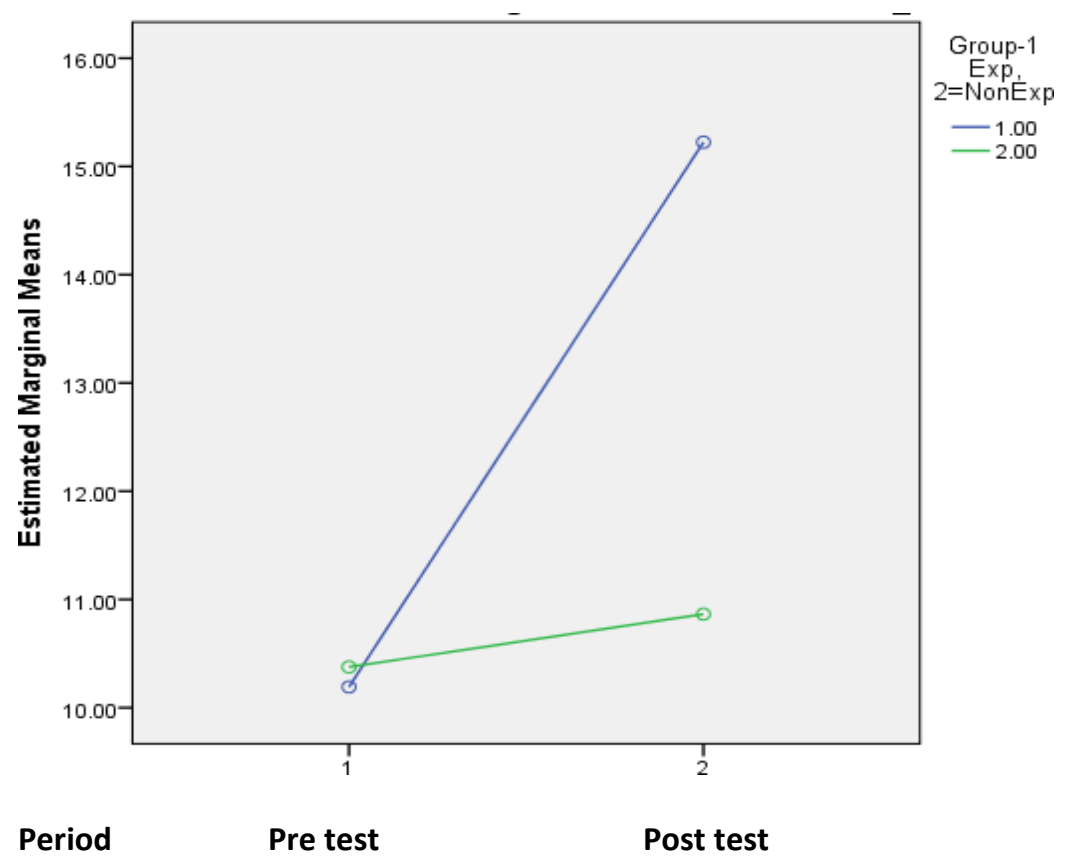

Trends of mean practice within and between of both groups 


\section{ARTICLES}

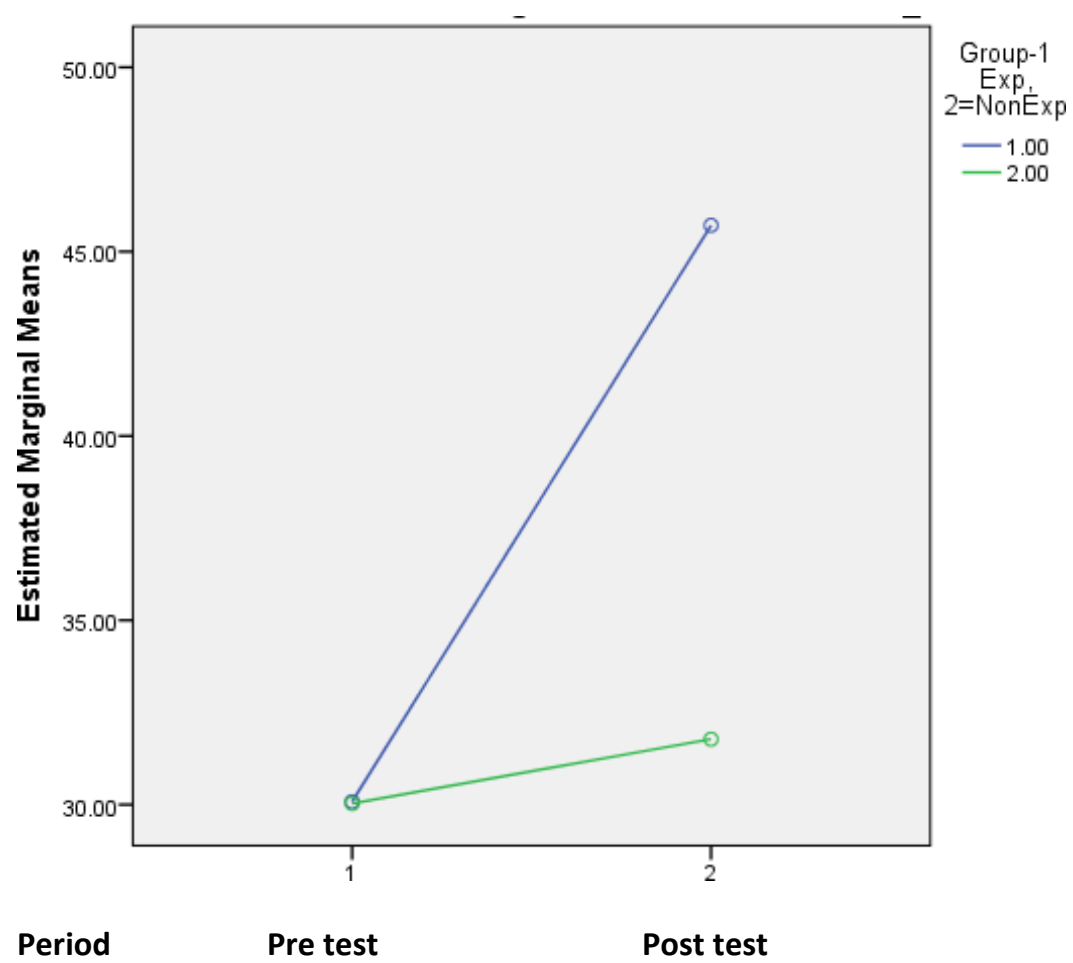

MAJOR FINDINGS The mean knowledge of experimental group at pre test was $14.5 \pm 2.3$ and at post test was 23.8 \pm 2.5 . From the mean score it is cleared that the patients in experimental had a higher level of knowledge after video assisted

Education. The mean improvement of knowledge was 9.3 \pm 3.2 . In respect of non-experimental group pre and posttest means were $15.0 \pm 2.1$ and $15.4 \pm 2.0$. The mean improvement was $0.4 \pm 0.8$. The improvements of both groups were statistically very highly significant $(\mathrm{P}<0.001)$. The $\mathrm{t}^{\mathrm{t}}$ value of experimental group the knowledge score is 32.273 . This value is significant at 0.005 level at $124 \mathrm{df}$. This indicates that the difference in level of knowledge scores of experimental after Video assisted programme is highly significant.

\section{Level of Attitude:}

The mean attitude of experimental group at pretest was $10.2 \pm 2.0$ and non-experimental group was 10.4 \pm 2.1 . The difference of means are not statistically significant $(P>0.05)$. The mean attitude improvement of both groups at Post tests were $15.2 \pm 1.2$ and $10.9 \pm 1.8$. From the mean score it is cleared that the patients in experimental had a higher level of attitude after video assisted education the differences of means between the two groups at posttest were statistically very highly significant $(\mathrm{P}<0.001)$. The ${ } \mathrm{t}^{\prime}$ value of experimental group the knowledge score is 22.416 .This value is significant at 0.005 level at $248 \mathrm{df}$. This indicates that the difference in level of attitude scores of experimental after Video assisted programme is highly significant.

\section{Level of Practice:}

Table 4.3.5shows that the mean practice of experimental group at pretest was $30.1 \pm 4.7$ and non-experimental group was $30.4 \pm 4$.7.The difference of means is not statistically significant $(P>0.05)$. From the mean score it is cleared that the patients in experimental had a higher level of practice after video assisted education. The mean 


\section{ARTICLES}

practice improvement of both groups at post tests were $45.7 \pm 5$.5and 31.8 \pm 4.1 . The differences of means between the two groups at posttest were statistically very highly significant $(P<0.001)$. The ${ }{ }^{t}$ value of experimental group the knowledge score is 22.807 .This value is significant at 0.005 level at $248 \mathrm{df}$. This indicates that the difference in level of practice scores of experimental after Video assisted programme is highly significant.

\section{CONCLUSION}

The study concluded that video assisted programme is more effective in changing the level of knowledge of diabetic cases. Also statistically proved that video assisted programme is more effective in changing the attitude and practice of diabetic cases..

\section{RECOMMENDATIONS}

1. A similar study can be replicated on a large sample to validate and generalise findings.

2. A similar study can be undertaken for an extended period of time.

\section{REFERENCES}

1. Asemi Z Tabassi Z Samimi M Fahiminejad T esmaillzadeh A. Research centre for Biochemistry and Nutrition in metabolic diseases, kasshan university of medical sciences kashan Iran. PMID 23148885 [ Pub Med-as supplied by publisher]

2. Basavanthappa, B.T (1998). Nursing Research, 1st. Ed.). New Delhi: Lord Son publishers private Ltd.86- 93.

3. Belton, A. \& Simpson, N. (2003).How to do Patient education. A Guide and book. Toronto: Belton \& Associates.13-20.

4. Black, J.M., Hawks, J.H., \& Annabello, M. (2007), Medical and Surgical Nursing, (7th.ed.)London: W. B Saunders.1102-1118.

5. Denise, P.F. (2004). Nursing Research principles and methods. (7th .ed.)

6. Funnel MM, Brown TL, Childs BP, Haas LB, Hosey GM, Jensen B, et al. National standards for diabetes selfmanagement education. Diabetes care 2009; 32suppl 1:S87-94. CrossRef pubMed

7. Salina SG Browning CJ Yasin S. Department of Family Medicine University Putra Malaysia Serdang Selangor Malaysia. 